\title{
Literatura y realidad: el cuento maravilloso
}

\author{
por Ana Zapata
}

\section{Introducción}

"Le réalisme est un type de discours qui voudrait se faire passer pour un autre: un discours dont l'être et le paraître ne coïncident pas"'.

Para los escritores del XVIII y del XX, así como para sus lectores, el realismo en literatura es un ideal: ideal de representación fiel de la realidad, ideal del discurso verídico, perfección hacia la cual tienden todos los discursos.

El realismo de la obra literaria no reside en el género de vida que representa, sino en la manera en que lo hace. La pobreza de las convenciones formales de esa obra es el precio que debe pagar, en ocasiones, por ese realismo.

Las diferentes formas literarias imitan la realidad en grados muy diversos. La gran mayoría de los lectores encuentran en la novela, "le roman", la forma literaria más adecuada para contentar sus deseos de una correspondencia estrecha entre la vida y el arte.

R. Jacobson ${ }^{2}$ dice:

"el realismo en literatura es principalmente una cuestión de convención estética, un tipo de programa o de concepto táctico invocado por una generación de escritores para desmarcarse de una generación precedente y de la que consecuentemente es vano buscar criterios formales específicos, teniendo que asumir ciertamente la relatividad de la noción de realismo" (pp. 31-39).

T. Todorov ${ }^{3}$ distingue tres aspectos en la literatura:

* fantástico, que es un balanceo continuo entre lo real y lo sobrenatural, conservando un elemento realista como polo de oposición interna.

* maravilloso, que es un monopolio permanente de lo sobrenatural.

* extraño, que es lo sobrenatural explicado de un modo racional.

Así pues, el autor fantástico puede explícitamente señalar la fantasía de su discurso a través de llamadas a un corpus o a un género culturalmente constituido. El autor realista, por el contrario, no dispone de este recurso: deberá apoyarse en las ciencias, en la

(1) R. Barthes, L. Bersani, y otros: Littérature et réalité. Paris, éditions de Seuil, 1982.

(2) R. Jacobson, Questions de poétique. Paris, éditions de Seuil, 1973.

(3) T. Todorov, Introduction á la littérature fanlastique. Paris, éditions de Seuil, 1970, p. 80 ss. 
historia, y sus citas se limitan a él mismo.

Al plantearnos la cuestión del realismo en literatura, nos encontramos con frecuencia con la oposición verdadero/falso.

Siguiendo a Todorov, las frases de un texto literario han de someterse a "l'épreuve de vérité". Dicho de otro modo, cuando un libro comienza por una frase como "Juan estaba en la habitación acostado sobre la cama" no debemos plantearnos la cuestión sobre si es cierto o es falso. El lenguaje literario es un lenguaje convencional, en el que la prueba de veracidad es imposible: la verdad es una relación entre las palabras y las cosas que designan, y, en literatura, estas cosas no existen.

Por el contrario, la literatura conoce una exigencia de validez o de coherencia interna: si en la página siguiente de ese mismo libro imaginario se nos dice que no hay ninguna cama en la habitación, el texto no responde a la exigencia de coherencia.

Lo fantástico nos sitúa ante un dilema: ¿creer o no creer? Lo maravilloso realiza esta unión imposible, proponiendo al lector creer sin creer verdaderamente.

Para Lovecraf, un cuento es fantástico simplemente si el lector siente profundamente un sentimiento de temor y de terror, si siente la presencia de mundos y de poderes insólitos.

Todas estas ideas sobre la realidad, sobre fantasía, sirven para adentrarnos en el campo nada fácil de la cuentística popular, de los cuentos maravillosos tan diferentes en ocasiones y tan parecidos en otras a las narraciones fantásticas o a las novelas realistas.

La mayor parte de los cuentos pertenecen a un fondo común que se encuentra bajo diversas formas en Europa y en otras latitudes.

Las investigaciones sobre el origen de los cuentos tienen como punto de partida dos constataciones "extrañas": por un lado, la existencia de un mismo motivo en diferentes puntos del globo, a menudo bastante alejados $y$, por otro lado, ja irracionalidad de numerosas narraciones.

Se han barajado distintas teorías (indo-europea, defendida por Max Müller, indianista, de la que $\mathrm{T}$. Benfey es el representante) pero sin duda alguna, es la tesis presentada por V. Propp la que tendrá mayor número de seguidores.

Propp ${ }^{4}$ opina que los cuentos maravillosos guardan el recuerdo de "croyances et de rituels primitifs", pero que nacieron más tarde, en los albores de la era agrícola, en sociedades que, lejos de tener esas creencias y olvidando la práctica de esos ritos, no los comprenden ya, y los deforman progresivamente para explicarlos según sus propios esquemas culturales.

El origen de numerosos cuentos, remonta ciertamente a un pasado lejano, muy lejano y escapa a las investigaciones de los estudiosos.

El cuento popular se ha transmitido por vía oral en tanto que ha formado parte de una cultura viva y no es, sino por azar, que encontramos algunos vestigios profundamente transformados en una obra escrita.

El folklorista dispone de tres fuentes fundamentales para el estudio de los cuentos populares. La recopilación de historias, llevada a cabo en la segunda mitad del siglo

(4) V. Propp, Morphologie du conte. Paris, Seuil, 1970. 
XIX y primera del XX, nos aporta un material bastante amplio, aunque no hay que olvidar que los textos recogidos y anotados pertenecen a una tradición oral que ya ha sufrido la influencia de una cierta tradición escrita.

Los documentos no aportan más que la fecha de los primeros testimonios escritos. Pero esta fuente exige una gran prudencia metodológica.

\section{El cuento popular en Francia: Perrault}

En general, los cuentos franceses son menos extraños, más familiares que los de otros países.

Los seres sobrenaturales aparecen con poca frecuencia con relación a los cuentos alemanes o incluso a los rusos.

Los protagonistas de los cuentos franceses mantienen disputas con ogros e incluso con el diablo. Los ogros aparecen normalmente como gigantes y se caracterizan fundamentalmente por alimentarse de carne humana. Por lo que se refiere a las hadas, verdaderas protagonistas en los cuentos maravillosos de un gran número de países, son menos frecuentes de lo que cabe esperar en la tradición oral.

Los cuentos tradicionales se sitúan, generalmente, en un medio modesto, a menudo rural. Esta ambientación limita en cierta medida, el estilo de los cuentistas, que recurren a fórmulas propias de la lengua familiar, no teniendo a penas en cuenta, los sucesos, los acontecimientos que se narran.

La lengua popular habla de "literatura popular" para designar todo un corpus literario que disfruta de una vasta audiencia fuera del círculo de los letrados.

Los folkloristas, por el contrario, designan con el nombre de cuento popular a un cierto tipo de narración en prosa referida a unos acontecimientos ficticios ya transmitidos oralmente.

La clase popular pretende, en alguna medida, hacer suyo este género, libre de todo artificio literario. Los cuentos de Perrault (La Cenicienta, Caperucita Roja, La Bella Durmiente...) no son sino adaptaciones muy literarias, profundamente expurgadas y modificadas. Este afán literario se contrapone a la idea que comentaba anteriormente de mantener este género dentro de una determinada clase social.

Es literatura y, por tanto, universal.

El cuento de Perrault se presenta como fruto de una gran elaboración literaria. La diversidad de sus cuentos no da en ningún momento la impresión de que el autor se repite, ya que a cada instante cambian el tiempo, la tonalidad, el equilibrio de las partes propiamente narrativas, los diálogos, los elementos descriptivos e incluso los pintorescos.

La extensión va desde las dos o tres páginas, hasta incluso a veces las más de diez. $\mathrm{La}$ acción en ocasiones se complica con numerosos e innecesarios rodeos; otras veces, por el contrario, se simplifica extremadamente.

El esperado final feliz, que se presenta como regla fija en este tipo de historias, es a menudo olvidado, apareciendo bruscos desenlaces como en Caperucita Roja.

La corte, la ciudad o el campo, el palacio, la casa burguesa o la choza, sirven indistintamente de marco a la historia. 
Todas las condiciones sociales, desde las más elevadas hasta las más humildes, todos los medios están representados.

Por todas partes, bajo la ficción, aftora, discretamente presente gracias a los objetos, los muebles, los detalles sobre la alimentación o el vestuario, la realidad contemporánea, que permite a la hechicería, a lo maravilloso, enraizarse en lo cotidiano y es gracias al contraste que se produce, que se valora mucho más ese mundo mágico.

Lo maravilloso es utilizado con sobriedad. Entre los personajes, sólo encontramos una decena de hadas, una de las cuales, acompañada por un enano, es arrastrada por los dragones; ogros, animales que hablan, como en las fábulas, conservando su forma de bestias pero presentando un comportamiento perfectamente humano. Por lo que se refiere a los objetos, exceptuando la indispensable varita mágica, no encontramos más que las botas de siete leguas y la llave de Barba azul, de la que se dice que es un hada.

Las moralejas en verso que aparecen al final de cada cuento, introducen una cierta disonancia irónica o se alejan de la narración que las precede.

J.P. Collinet dice:

"ninguna obra podría separarse con más facilidad de su creador para disfrutar tras su desaparición de una existencia autónoma.

Salida del patrimonio común, vuelve a él como por una tendencia natural ${ }^{5}$.

\section{Corrientes metodológicas}

V. Propp ${ }^{6}$ inaugura en cierto modo el vasto campo de las investigaciones estructuralistas sobre el cuento maravilloso. La constatación fundamental de este autor, que examina el cuento desde el punto de vista de su estructura, y no de su tema, es que el motivo es descomponible en varios elementos que constituyen una serie de constantes:
"les éléments constants, permanents, du conte, sont les fonctions des person- nages, quels que soient ces personnages et quelle que soit la manière dont ces fonctions sont remplies. Les fonctions sont les parties constitutives fondamen- tales du conte. Le nombre des fonctions que comprend le conte merveilleux est limite" (pp. $58 \mathrm{ss})$.

En la Morphologie du conte, Propp aplica este análisis funcional a un corpus de 100 cuentos populares rusos. Al término de éste, descubre que el cuento maravilloso ruso está constituido por 31 funciones que se enlazan en un orden idéntico.

Esta sucesión de funciones forma para él, el esquema canónico del cuento maravilloso ruso y, probablemente, del cuento maravilloso en general.

Para V. Propp las funciones actúan como los elementos constantes y estables de los cuentos populares. Son independientes del personaje que las realiza y del modo en que son llevadas a cabo. Son los elementos constitutivos del cuento. Para este autor, todos

(5) J. P. Collinet, prólogo a la edición de los Contes de Perrault. Paris, Folio, 1981, (p. 13-14).

(6) V. Propp, Morphologie du conte. Paris, Seuil, 1970. 
los cuentos de hadas, estudiados desde el punto de vista de su estructura pertenecen a un solo y único tipo.

En todo cuento maravilloso encontramos un prólogo que describe la situación inicial y que no es todavía una función.

En segundo lugar, aparecen siete funciones que constituyen una sección preparatoria: la ausencia, la prohibición, la transgresión, la solicitud de información, la información obtenida, el engaño, la complicidad involuntaria.

La acción propiamente dicha, empieza con la octava función, que reviste desde este momento una importancia fundamental: el malvado ocasiona un daño a un miembro de la familia (fechoría).

Propp define también el cuento como una narración que presenta sicte personajes, cada uno de los cuales tiene su propia esfera de acción. Su punto de vista estructuralista indica que sería mejor traducir esta palabra por "actantes", ya que evidentemente es la función de estos personajes y no su naturaleza lo que se estudia.

Los actantes serían pues, el agresor, el donante, el auxiliar, la princesa, el mandante, cl héroe y el falso héroe.

Al término de su análisis, Propp descubre que todos los cuentos maravillosos presentan la misma estructura. La función debe ser entendida como un acto de los personajes, definido desde el punto de vista de su significación por el desarrollo de la acción del cuento, considerado como un todo.

C. Bremond ${ }^{7}$ por su parte, intenta analizar y clasificar los cuentos maravillosos según unos criterios puramente formales. En el estado todavia embrionario de su investigación, espera llegar a un sistema único de clasificación morfológica de los cuentos maravillosos, reagrupando y jerarquizando los modos de caracterización adoptados.

La caracterización invariable es la que un acontecimiento, no importa cual, que acaba de producirse, lleva a cabo a lo largo de la narración.

La caracterización variable es la trama, en ocasiones la moraleja empleada en la producción y utilizada en las circunstancias que rodean este acontecimiento.

Lo que cuenta para él, por tanto, es saber qué es lo que realiza el personaje, es decir, qué función desempeña. Por invarible entiende una acción cuya función es la de introducir otra, que asumirá a su vez la misma función con respecto a otras sucesivas.

Pero surgen nuevas tendencias. Para los psicoanalistas, la mitología y el folklore constituyen un material privilegiado.

Según B. Bettelheim ${ }^{8}$ :

"los cuentos de hadas están caracterizados por plantear problemas existenciales en términos breves y precisos" (pp. 198 ss).

La moralidad del cuento está asegurada por el hecho de que el niño imagina que él participa de todos los sufrimientos del héroe a lo largo de sus tribulaciones y que triunfa con él en el momento en el que la virtud se impone ante el mal. El niño lleva a

(7) C. Bremond, Logique du récit. Paris, Seuil, 1973.

(8) B. Bettelheim, Psychanalyse des contes de fées. Paris, Laffont, 1976. 
cabo individualmente esta identificación y las luchas interiores y exteriores del héroe imprimen en él el sentido moral.

En los cuentos de hadas, los personajes presentan unos caracteres muy extremos: o son buenos del todo o, por el contrario, no existen personajes tan malvados como ellos.

La yuxtaposición de personajes tan opuestos no tiene como misión el subrayar la postura más loable. Este contraste permite al niño comprender de un modo más fácil sus diferencias y entenderlas mucho mejor si los protagonistas, como en la vida real, se presentan con toda su complejidad.

El lector se identifica con el "bueno" no en razón de su virtud, sino porque la situación del héroe encuentra en él un eco profundo. El protagonista está sujeto a accesos desesperados de soledad y abandono, y es a menudo presa de angustias mortales.

Los cuentos de hadas toman muy en serio estas angustias y estos dilemas existenciales y los aborda directamente: la necesidad de ser amado y el miedo a ser considerado como un "bon à rien"; el amor a la vida y el miedo a la muerte.

El cuento maravilloso presenta soluciones que el niño puede tomar según su nivel de comprensión. Estos cuentos le suministran orientación hacia el futuro y le sirven de guía. Le ayudan a renunciar a sus deseos infantiles de dependencia al mismo tiempo que les ayuda a llegar a conseguir una existencia independiente más satisfactoria.

La importancia que un cuento puede tener para un cierto niño y a una edad particular depende de su nivel de desarrollo psicológico y de sus problemas dominantes en ese momento.

Los cuentos de hadas enriquecen la vida del niño y generan un "encantamiento" únicamente porque él no sabe bien cómo esos cuentos han podido ejercer sobre él su encanto.

G.K. Chesrton y C.S. Lewis opinan que los cuentos maravillosos son exploraciones espirituales y por lo tanto muy parecidos a la vida, ya que revelan la existencia humana como si fuera contemplada, sentida o adivinada desde el interior.

Las maravillosas historias de hadas dirigen al niño hacia el descubrimiento de su identidad y de su vocación y le muestran también las experiencias por las que debe pasar para desarrollar más adelante su carácter.

Estos cuentos maravillosos nos dicen que, a pesar de la adversidad, una buena vida, llena de consolaciones está en nuestras manos, a condición de que no esquivemos los combates llenos de riesgos sin los cuales no encontraríamos jamás nuestra verdadera identidad.

Durante la mayor parte de la historia humana, la vida intelectual del niño, a parte de sus experiencias inmediatas en el seno de su familia, reposaba en historias míticas y religiosas y en los cuentos de hadas.

Esta literatura tradicional alimentaba la imaginación del niño y la estimulaba. Como estas historias respondian a los planteamientos que fundamentalmente se cuestionan estos niños, se presentan como un agente primordial de su socialización.

En los cuentos de hadas, los procesos internos del individuo son exteriorizados y llegan a ser comprensibles, porque son presentados por los personajes y los acontecimientos de la historia.

"las virtudes terapéticas del cuento de hadas aparecen en el momento en el que 
el paciente encuentra sus propias soluciones al pensar en lo que la historia le da a entender sobre él mismo y sobre sus confictos internos en un momento determinado de la vida". (pp. $287 \mathrm{ss})^{9}$

Los cuentos maravillosos, según los críticos psicoanalistas, no se refieren claramente al mundo exterior, aunque comiencen de un modo realista o estén plagados de hechos cotidianos.

Estas historias tienen la finalidad de procurar una serie de informaciones útiles sobre el mundo exterior sino que pretenden senalar y subrayar los procesos internos de la obra en un individuo.

Algunos cuentos de hadas o ciertas historias folklóricas, evolucionan a partir de mitos; otros, por su parte, son incorporados a ellos. Las dos fórmulas encarnan la experiencia acumulativa de una sociedad en la que los hombres quieren recordar y mantener presente la sabiduría del pasado y transmitirla a las generaciones futuras.

El cuento de hadas se presenta bajo una forma simple, familiar; el oyente no está sometido a ninguna exigencia. Esto evita que el joven lector se sienta obligado a actuar de un modo particular y no le lleva en ningún momento a sufrir un sentimiento de inferioridad. Estas historias maravillosas le reafirman, le dan la esperanza para el futuro y contienen la promesa de una conclusión feliz.

Las historias maravillosas fortalecen a los niños, mostrándoles que, finalmente, pueden ser superiores a los gigantes, es decir, que pueden creer y ser ellos mismos, como gigantes, adquiriendo sus mismos poderes. Estos últimos son "the mighty hopes that make us men". ${ }^{10}$

El joven lector, familiarizado con estas narraciones maravillosas comprende que se dirigen a él en un lenguaje simbólico, lejos de la realidad cotidiana (ningún niño es obligado a acostarse sobre cenizas, como en La Cenicienta).

"Erase una vez ...", "En un país lejano ...", "Erase una vez, en un viejo castillo en medio de un espeso bosque ...", estos comienzos dejan claramente expuesto el hecho de que lo que se va a narrar escapa a las realidades inmediatas que nosotros conocemos. Esta imprecisión nos muestra de manera simbólica que abandonamos el mundo de lo concreto, de la realidad cotidiana. Los viejos castillos, las profundas cavernas, las habitaciones cerradas en las que está prohibido entrar, los bosques impenetrables, sugieren que se nos va a revelar algo que normalmente se nos esconde, mientras que "sucedió hace mucho tiempo ..." implica que vamos a conocer sucesos bastante arcaicos.

El cuento de hadas se lanza a acontecimientos fantásticos. Pero, a pesar de los largos rodeos no se pierde en ningún momento el hilo de la historia. El niño, tras haberse dejado arrastrar por un viaje maravilloso, vuelve a la realidad al final del cuento. Sacará en conclusión que uno puede sin peligro alguno, dejarse arrastrar por la imaginación, a condición de no rendirse a ella y quedar eternamente prisionero.

Al final de la historia el héroe regresa a la realidad, a una realidad feliz, despojada de toda magia:

(9) B. Bettelheim, op. cit.

(10) "Las poderosas esperanzas que nos hacen hombres". A. Tennyson: In memoriam. 
"lorsque les désirs les plus ardents de l'enfant sont personnifiés par une bonne fée, lorsque toutes ses pulsions destructives le sont par une méchante sorcière, toutes ses peurs par un loup vorace (...) l'enfant peut alors commencer enfin à mettre de l'ordre dans ses tendences contradictoires. Et, à partir de là, il sera de moins en moins submergé par un chaos irréductible"11

Algunos piensan que los cuentos de hadas son nocivos porque no presentan la pintura "verdadera" de la realidad. Pero estos críticos no comprenden que los cuentos maravillosos no intentan describir el mundo exterior ni la realidad.

La verdad de las historias de hadas es la de nuestra imaginación y no la de una causalidad normal.

Tolkien ${ }^{12}$ a propósito de la pregunta ¿es verdad? señala:

"no se puede responder a la ligera, de modo inconsiderado".

Este autor opina que el niño quiere ante todo distinguir entre lo que está mal y lo que está bien. Para el niño nada es más verdad que lo que él desea. Cuando el niño pregunta sobre la veracidad de una historia, basta generalmente con explicarle que esas historias no suceden en nuestros días, ni en el mundo en el que vivimos, sino en un país inaccesible.

Los cuentos de hadas sufrieron grandes críticas cuando los nuevos descubrimientos del psicoanálisis y la psicología infantil revelaron hasta qué punto puede ser violenta la imaginación del niño, angustiada, destructiva, e incluso llegar a veces a los límites del sadismo.

Los elementos más estables de los cuentos de hadas tradicionales son para Tolkien: la imaginación, la cura, la liberación y el consuelo. Hablando del desenlace final feliz, este autor piensa que todas las narraciones maravillosas deben tener uno.

"Se podría añadir un elemento más a la enumeración de Tolkien; es necesario que exista una amenaza, una amenaza dirigida contra la existencia física del héroe, contra su existencia moral ${ }^{\text {"13 }}$

No hay en la vida una amenaza mayor que la de ser abandonado, la de quedarse solo en el mundo. El psicoanálisis llama a este gran temor del hombre "l'angoisse de séparation"; cuanto más jóvenes seamos, más atroz es nuestra angustia cuando nos sentimos abandonados.

El nifio se arriesga incluso a perder su vida cuando no está convenientemente protegido y cuidado. Por este motivo, el consuelo es el mayor servicio que el cuento de hadas puede rendir al nifio.

Tolkien dice ${ }^{14}$ :

(II) B. Bettelheim, op. cit. p. 119.

(12) J.R.R. Tolkien: Tee and leaf. Boston, Houghton Mifflin, 1965.

(13) B. Bettelheim, op. cit. p. 250.

(14) J.R.R. Tolkien, op. cit. pp. 235 ss. 
"Les choses prennent soudain une tournure joyeuse ... Quelque fantastique et terrible qu'ait pu être l'aventure, l'auditeur, qu'il soit enfant ou adulte, retient son souffle quand vient ce virage, son coeur se met a battre, est souleve, et il n'est pas loin des larmes"

\section{Conclusiones}

La gran mayoría de los cuentos modernos tienen un final triste, que no aporta ni la liberación ni el consuelo que los acontecimientos aterradores del cuento de hadas presentan irremisiblemente, y que proporcionan al niño las fuerzas necesarias para afrontar las vicisitudes de la vida.

En el cuento maravilloso tradicional, el héroe es recompensado y el malvado sufre una suerte merecida, lo que satisface al niño, que tiene una profunda necesidad de ver triunfar a la justicia.

Por otro lado, habría que señalar que existe todo un arte de contar cuentos de hadas. Para que estas historias aporten la máxima confortación, para que tomen toda su significación simbólica y, sobre todo, todo su sentido interpersonal, es preferible contar estas historias a leerlas.

"El cuento maravilloso folklórico es el resultado de una historia que ha sido remodelada sin cese a fuerza de ser contada millones de veces por diferentes adultos a otros adultos y a niños.

Cada narrador al contar la historia, elimina y añade ciertos elementos para volver la historia más significativa para él mismo y para sus auditores, a los que conoce bien"15.

$\mathrm{Si}$, por el contrario nos mantenemos fieles al texto impreso, reducimos cualitativamente las posibilidades de los cuentos.

Los esfuerzos de los hermanos Grimm dejaron una secuela de corrientes interpretativas, todas ellas inmersas en el espejismo del cuento original, su procedencia, sus migraciones, sus pasos contados por el ancho devenir de la Historia.

Un verdadero mito científico que venía a enmarañar un poco más, si ello era posible, el cúmulo de preguntas que de por sí despierta la simple lectura de los cuentos y sus inevitables referencias culturales.

Todavía hoy, y a pesar de V. Propp, el cuento popular o folklórico no acaba de encontrar su sitio y le es de entera aplicación lo que Lévy-Strauss dijera a propósito de la antropología hace ya bastante tiempo:

"La antropoloía ocupa, de buena fe, ese campo de la semiología que la lingüística no ha reivindicado todavía para sí, a la espera de que, para ciertos sectores al menos de dicho dominio, se constituyan ciencias especiales".

(15) B. Bettelheim, op. cit. pp. 328. 
Lévy-Bruhl resume bastante bien el punto de partida de los mitólogos de comienzos de siglo, para quienes el mito es parte esencial del ritual mágico, especialmente en los ritos de iniciación y en el culto a los muertos; el cuento sería una forma derivada del mito, una vez rota la prohibición de ser contado:

"Los mitos constituyen literalmente el tesoro más precioso de la tribu. Se refieren al núcleo mismo de lo que la tribu venera como su cosa más sagrada. Los mitos más importantes sólo los conocen los ancianos que guardan celosamente su secreto".

La relación entre mito y cuento, advertida hace mucho tiempo, generó por los años sesenta una discusión entre Propp y Lévy-Strauss, sobre la base de una presunta antinomia, entre formalismo y estructuralismo que, transcurridos algunos años, se ha visto poco consistente. Mientras el formalista opina que los cuentos maravillosos derivan históricamente de un mito, Lévy-Strauss lo más que está dispuesto a admitir es que el cuento es una versión reducida del mito, dado que una narración puede ser un mito en una determinada sociedad, mientras que en otra es un cuento.

Depende de las necesidades de cada pueblo, y no es el paso del tiempo lo que debilita o transforma estos relatos de una cosa en otra. Incluso se llega a admitir la acción recíproca de una forma sobre otra en una misma área.

Según J. Bellemin-Noël ${ }^{16}$ los cuentos comparten con los mitos y las leyendas "la particularité d'étre des histoires exemplaires que les sujets utilisent comme des canevas".

La originalidad del cuento es que formula y actúa al mismo tiempo, teoriza y cumple representaciones de deseo, tanto en el que las ha imaginado, como en los que lo representan, o en los que lo saborean.

El niño que lee no hace otra cosa que investigar. Los cuentos les enseñan que los impulsos del placer y los altibajos de la realidad, son comunes a todos.

En este tipo de historias, las maravillosas, los personajes saben y nosotros también cómo será el desenlace final: feliz, por supuesto.

Escuchamos $\sin$ fin estas narraciones, leemos sin descanso, sin fatiga.

La ficción de los cuentos no plantea ninguna interrogación, de ningún tipo, porque ella es en sí misma, por entero, una interrogación.

(16) J. Bellemin-Nöel, Les contes et leurs fantasmes. Paris, P.U.F., 1983. 